\title{
A Coherent FM Laser Radar Based System for Remote Metrology in ITER*
}

\author{
R. E. Barry, T. W. Burgess, and M. M. Menon \\ Robotics \& Process Systems Division \\ Oak Ridge National Laboratory \\ Post Office Box 2008 \\ Oak Ridge, Tennessee 37831-6304 \\ A. Slotwinski and R. Sebastian \\ Coleman Research Corporation \\ 6551 Loisdale Ct., Suite 800 \\ Springfield, Virginia 22150
}

\begin{abstract}
The submitted manuscript has been authored by a contractor of the U. S. Government under contract DE-AC0584OR21400. Accordingly, the U. S. Government retains a paid-up, nonexclusive, irrevocable, worldwide license to publish or reproduce the published form of the public, and perform publicly and display publicly, or allow others to do so, for U. S. Government purposes.
\end{abstract}

To be presented at the SOFE at the University of Illinois

\section{DISCLAIMER \\ on October 2-6, 1995}

This report was prepared as an account of work sponsored by an agency of the United States Government. Neither the United States Government nor any agency thereof, nor any of their employees, makes any warranty, express or implied, or assumes any legal liability or responsibility for the accuracy, completeness, or usefulness of any information, apparatus, product, or process disclosed, or represents that its use would not infringe privately owned rights. Reference herein to any specific commercial product, process, or service by trade name, trademark, manufacturer, or otherwise does not necessarily constitute or imply its endorsement, recommendation, or favoring by the United States Government or any agency thereof. The views and opinions of authors expressed herein do not necessarily state or reflect those of the United Stätes Government or any agency thereof.

* Research sponsored by the Office of Fusion Energy, and the Office of Technology Development, U.S.

Department of Energy, under contract DE-AC05-84OR21400 with Lockheed Martin Energy Systems, Inc.

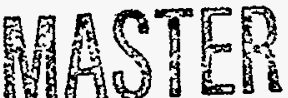




\title{
A Coherent FM Laser Radar Based System for Remote Metrology in ITER*
}

\author{
R. E. Barry, T. W. Burgess, and M. M. Menon \\ Oak Ridge National Laboratory, Robotics and Process Systems Division \\ P.O. Box 2008, Oak Ridge, TN 37831-6304 \\ A. Slotwinski, and R. Sebastian \\ Coleman Research Corporation, Springfield, Virginia 22150
}

\begin{abstract}
The plasma facing surfaces in ITER must be aligned to millimeter accuracy with respect to the magnetic flux surfaces to prevent impurity influx into the plasma and to avoid component damage. Checking of in-vessel component alignment during initial assembly, operation, and subsequent maintenance is anticipated. A fully remote metrology system is necessary, particularly since major remote operations such as shield blanket exchange and divertor cassette replacement are planned. The metrology system must be compatible with the ITER in-vessel environment of high gamma radiation $\left(-10^{6}\right.$ $\mathrm{R} / \mathrm{hr})$, super-clean ultra-high-vacuum $\left(\sim 10^{-8} \mathrm{Torr}\right)$, and elevated temperature $\left(-200^{\circ} \mathrm{C}\right)$. A fast scanning rate is required since the plasma facing surface in ITER is very large $\left(-1500 \mathrm{~m}^{2}\right)$. A coherent FM laser radar based metrology system, developed by Coleman Research Corporation, is being adopted to accomplish this task. Conceptually, this metrology system consists of a compact (few $\mathrm{cm}^{3}$ ) remotely deployed laser transceiver optics module, linked through fiber optics to the laser source and imaging units that are located outside the biological shield. Range measurements conducted on a variety of surfaces using the system have yielded sub-millimeter accuracy. Therefore, the technique will easily meet the precision requirement for the ITER application. Computer simulations have been carried out to determine the optimum number of units required for complete mapping of the plasma facing surfaces. Most in-vessel components of the system appear to be radiation hardenable and vacuum compatible. Details of the system and developments required to make it fully compatible for ITER metrology application will be elaborated.
\end{abstract}

\section{INTRODUCTION}

The ITER vacuum vessel is a toroid with roughly D-shaped crosssection, as shown in Fig. 1. The maximum height of the plasma facing surfaces inside the $D$ is about $13 \mathrm{~m}$, and the width is about 6 $\mathrm{m}$. The major radius of the plasma is $8.1 \mathrm{~m}$. Precise alignment of plasma facing components inside the torus with respect to the magnetic field lines and the plasma is necessary for the successful operation of the reactor. Even small misalignments $(<1 \mathrm{~mm})$ can cause significant material erosion, precipitating serious problems with plasma operation due to impurity accumulation. Misalignment could also result in damage to certain crucial components. Checking the in-vessel component alignment, during assembly, maintenance

* Research sponsored by the Office of Fusion Energy, and the Office of Technology Development, U.S. Department of Energy, under contract DEAC05-840R21400 with Lockheed Martin Energy Systems, Inc. and operation are anticipated. A controlled 3D metrology system, that can be remotely deployed to perform accurate mapping of the ITER in-vessel components and their support structures (i.e., vacuum vessel, blanket/shield, divertor, etc.) is required. Inspection/viewing of plasma facing surfaces is also anticipated for troubleshooting during plasma operation.

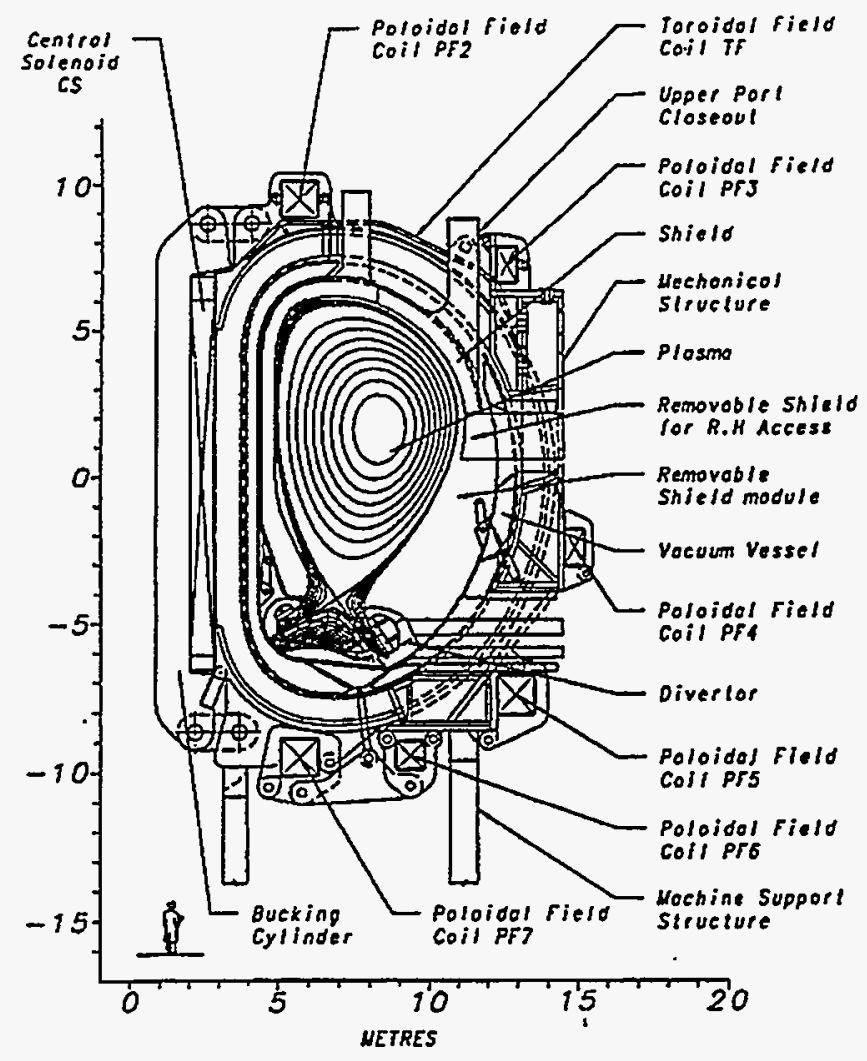

Figure 1. - Cross Section of ITER Vacuum Vessel

Apart from the need to measure the dimensions accurately, routine inspection of the plasma facing surfaces is also anticipated. For example, in JET, periodic viewing of the plasma facing surfaces, to speedily survey their condition without disturbing the operating conditions, is shown to be a valuable diagnostics tools. It will be shown that a precise metrological map of a surface can also be used as a visual image of the surface. As will be made clear later, the metrology system that is being developed for ITER requires no external illumination for producing "picture-quality" images - a distinct advantage for inspection in the in-vessel reactor environment. 


\section{METROLOGY SYSTEM REQUIREMENTS}

The in-vessel surface area of ITER that needs to be mapped is very large $\left(-1500 \mathrm{~m}^{2}\right)$. Minimizing the time required to complete a scan is an important consideration. The aim is to complete a rough scan (about one point per $\mathrm{cm}^{2}$ ) and compare the results against a previous scan during an $8 \mathrm{hr}$ shift. One may then more closely examine any area that appears suspicious by performing additional, higher resolution scans. As mentioned before, plasma purity considerations require that the alignment be accurate to sub-millimeter levels. ITER metrology requirements documentation calls for an accuracy of 0.1 $\mathrm{mm}$ for metrology. Since external access ports are limited and rapidly filling with other diagnostic equipment, a minimal set of metrology probes is desirable. To minimize the number of probes as well as to minimize the time to complete a scan, it is desirable for the range of the probe to be up to $20 \mathrm{~m}$. Thus, maintaining an accuracy of $0.1 \mathrm{~mm}$ in range measurements from ranges of up to about $20 \mathrm{~m}$ is a basic requirement.

The same considerations outlined in the above paragraph demand that the technique be accurate in a wide range of angles. Also, the range measurements should not be affected by differences in material surfaces as different types of plasma facing components are anticipated in ITER.

A cryostat surrounds the vacuum vessel and human access is permitted only outside the walls of this cryostat. For metrological mapping of the divertor throat area, kinematics studies suggest that the probes be installed from vertical ports. Although the details of the probe deployment scheme are yet to be designed, the above geometrical constraints dictate that the probe be capable of long travel $(-20 \mathrm{~m})$ and the absolute location of the probe position with respect to the plasma facing surface be known to $0.1 \mathrm{~mm}$ accuracy.

Other environmental considerations include very high levels of gamma radiation, ultra-high-vacuum, and elevated temperature. Soon after the start of ITER, the in-vessel environment of ITER will be highly radio-active due to neutron activation of the metallic wall that envelops the plasma. The gamma radiation level, $24 \mathrm{hr}$ after shutdown of the reactor, is estimated to be about $3 \times 10^{6} \mathrm{R} / \mathrm{hr}$. This is about 2-3 orders of magnitude higher than radiation levels encountered in typical fission reactors. The metrology/viewing system must be fully compatible for remote operation in this environment. The components must also be compatible with the clean ultra-high-vacuum (UHV) conditions that must be maintained in the torus. Elevated temperatures $\left(-200^{\circ} \mathrm{C}\right)$ are also expected within the torus. Although intense neutron radiation will also be present during reactor operation, the metrology system will be located in an area that is fully shielded from the neutrons.

\section{MEASUREMENTS USING COHERENT FM LASER RADAR}

A comparative evaluation of the various metrology techniques was conducted with the aim of selecting an appropriate technique for ITER. Techniques based on ultra sound, structured light, and time of flight using laser beams, were evaluated. This study revealed that frequency modulated (FM) coherent laser radar (CLR) based technique $^{2}$ has the most potential for ITER in-vessel metrology application. In such a scheme, the range is determined by measuring the shift in frequency of an FM laser beam. The accuracy in range is decided by the linearity of the frequency modulation over the counting interval. A prototype CLR system, developed for a joint DOE/NASA project by Coleman Research Corporation, was tested at ORNL in June of 1994. The results indicate that the basic technique is accurate enough to meet the ITER requirements. Since that time, Coleman has improved the ranging accuracy of the system.

The Coleman system is based on a coherent laser radar using a widely FM tunable laser diode $(1550 \mathrm{~nm})$. The basic configuration is shown in Fig. 2. The range is determined by measuring the shift in frequency between the transmitted and received components of an FM laser beam. Equations (1) and (2) describe the pertinent relationships

$$
\begin{aligned}
& f(t)=f(0)+(d f / d t) t \\
& t=2 R / c
\end{aligned}
$$

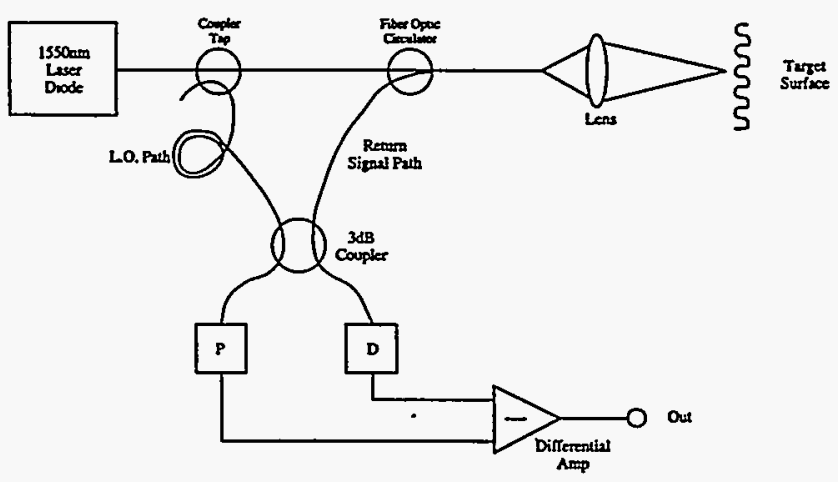

Figure 2. - Basic FM CLR

where $f(0)$ is the initial frequency, $f(t)$ is the frequency of the beam after a transit time $t,(\mathrm{df} / \mathrm{dt})$ is the linear modulation rate ${ }^{3}$. The range $R$ is determined from the transit time by using equation 2, knowing $c$ - the velocity of light. Coherent light waves, when combined correctly in an optical mixer, produce a beat frequency equal to the difference in frequency. Therefore,

$$
\mathrm{R}=\mathrm{c} \text { [beat frequency } / 2(\mathrm{df} / \mathrm{dt})]
$$

\section{A. Precision in Range Measurements}

Because of the difficulty in finding a "standard" with sufficient accuracy for comparison, the measurements were done as follows. An anodized aluminum plate surface was positioned at a nominal range of $4 \mathrm{~m}$. From this initial position, the object was moved in increments of $0.005 "(0.127 \mathrm{~mm})$ using a high precision linear positioner. At each position, 30 range measurements were taken using the prototype Coleman FM Laser Radar unit and the average range and the standard deviation were determined. The results, 
starting with nominal ranges of $4 \mathrm{~m}, 7.37 \mathrm{~m}$, and $12 \mathrm{~m}$, are shown in Fig. 3. The results show that the unit was able to measure the absolute range and track the precision movement $(0.127 \mathrm{~mm})$ accurately.

\section{Precision Range Test \#1}
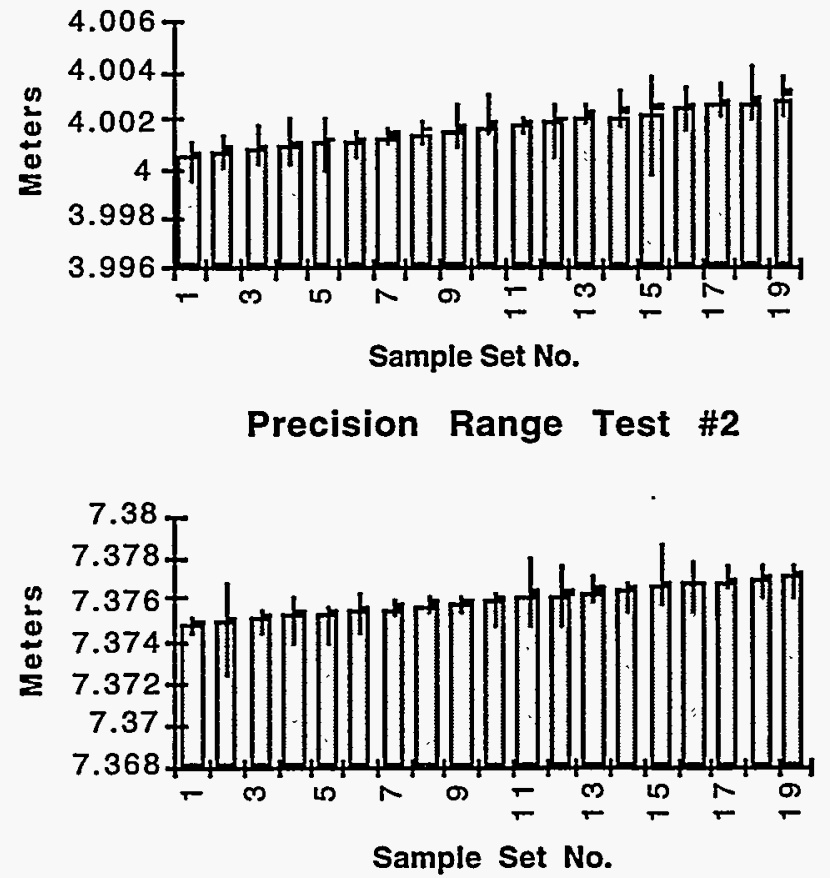

Precision Range Test \#3

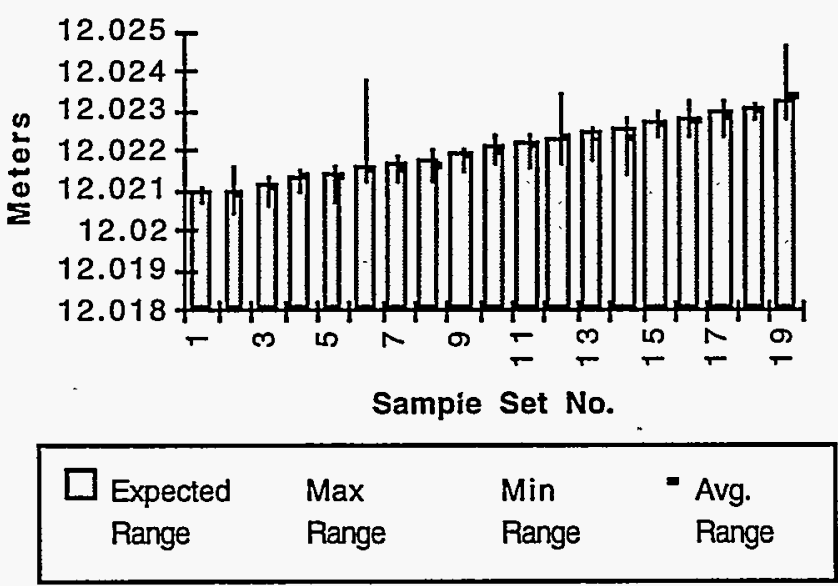

Figure 3. - Precision Range Measurement data

\section{B. Sensitivity to Different Material Surfaces}

In this set of experiments, the accuracy in range measurement is a concern only because of the dependence of the reflected signal strength on the surface reflectivity. In order to quantify the signal strength, a quantity called the "Quality Factor" was tracked over the measurement range. This factor is defined as:

\section{Quality Factor $=10 \log$ (Reflected signal Power/ Reference Power)}

Since the reference power is constant, a change in quality factor of $20 \mathrm{~dB}$ corresponds to a signal power difference by a factor of 100 .

The attenuation of the laser beam in air over a distance of $\sim 20 \mathrm{~m}$ is very small. However, scattering at the reflecting surface can significantly reduce the power of the reflected signal. For perfectly hemispherical scattering from the surface, over any given range, the signal will be reduced by the square of the ratio of the range. In a 2$15 \mathrm{~m}$ range, the maximum change in quality factor is thus $17.5 \mathrm{~dB}$. There was considerable scatter in the measured $Q$ factor, and therefore a linear regression analysis of the data was done to determine the trend. The results are shown in Table 1 . The attenuation in signal is well within the capability of the instrument to resolve.

\begin{tabular}{|l|c|}
\hline \multicolumn{2}{|c|}{ Table I - Materials Tested for Range Sensitivity } \\
\hline & $\begin{array}{c}\text { Equivalent } \\
\text { Signal Loss } \\
\text { (in db) }\end{array}$ \\
\hline Polished Aluminum Block & 9.93 \\
\hline Black Anodized Aluminum & 13.31 \\
\hline Steel Electrical Conduit (1 in. diam) & 11.55 \\
\hline White Bond Paper & 6.84 \\
\hline Corrugated Cardboard & 11.9 \\
\hline Styrofoam Block & 9.54 \\
\hline Green Ceramic Sheet (vinyl-like material) & 6.89 \\
\hline Weathered Concrete Block & 7.41 \\
\hline
\end{tabular}

\section{Angular Sensitivity}

In this test, the test piece was mounted on a rotational stage on an optics bench and the laser beam was positioned to strike the surface at the point of rotation. The test was performed at a range of roughly $7 \mathrm{~m}$, and the angle of incidence was varied in a wide range $\left(0-85^{\circ}\right)$. For a perfect cosine law reflector, the signal variation in the $0-85^{\circ}$ range is $10.6 \mathrm{~dB}$. The results obtained, using regression analysis of the data, are shown in Table II. The instrument was able to obtain range data at near grazing angles on most surfaces.

Table II-Materials Tested for Angular Sensitivity

\begin{tabular}{|l|c|}
\hline \multicolumn{1}{|c|}{ Material } & $\begin{array}{c}\text { Equivalent } \\
\text { Signal Loss } \\
\text { (in db) }\end{array}$ \\
\hline Rusted Angle Iron & 2.3 \\
\hline Polished Aluminum Block & 5.0 \\
\hline Black Anodized Aluminum & 3.47 \\
\hline Weathered Concrete Block & 0.06 \\
\hline
\end{tabular}




\section{Viewing Capability of the CLR system}

A metrological map of a surface with features can be converted into a "picture quality" image that helps to make visual assessment of the surface patterns. The CLR can be used to acquire images in a wide range of formats and resolutions. The prototype version has a pointing accuracy of $0.01^{\circ}$ and can be programmed to scan areas up to roughly $+1-40^{\circ}$ in azimuth and elevation. Scan patterns can be set up for raster type, serpentine, or discrete point scans. The data may then be used to produce high quality images of the surface. An image of a dime obtained by precision range scanning of its surface is shown in Fig. 4.

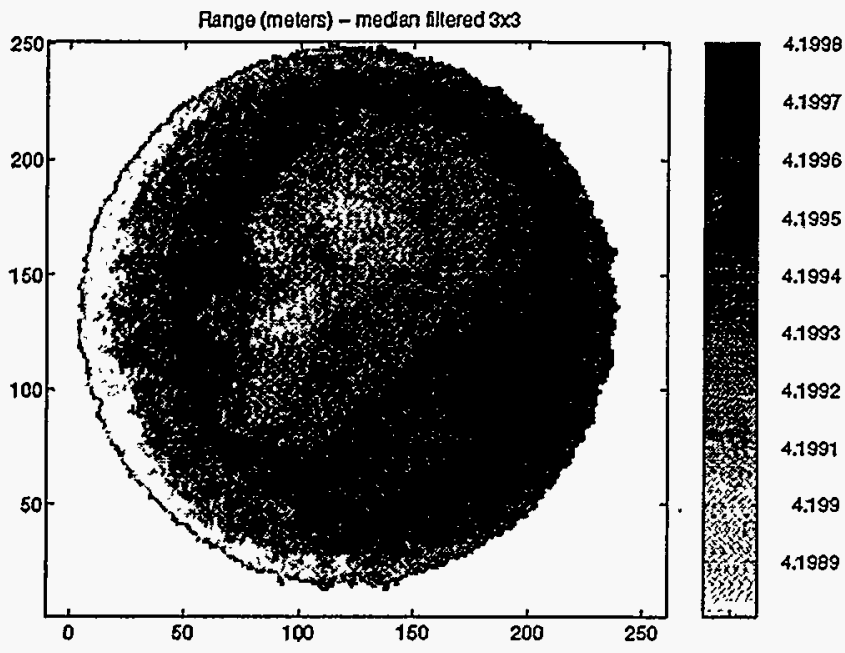

Figure 4. - Image of a dime taken with the Coleman CLR

\section{KINEMATICS STUDIES}

An important aspect the metrology system is to determine the number of metrology probes required for a complete view of all the plasma facing surfaces (about $1500 \mathrm{~m}^{2}$ ). It is also necessary to evaluate the time required for mapping the entire surface. These two aspects of the metrology system were examined using a computer simulation. A model was created of the ITER vacuum vessel with access ports, blanket/shield, and divertor. The model also included a sensor head with two degrees of freedom that permits positioning of the laser scanner device. This simulation arrangement was used to scan the plasma facing surfaces, particularly the divertor surfaces, from both horizontal and vertical port locations. The results show that vertical ports are required if the divertor throat areas are to be measured. Preliminary results suggest that a minimum of six probes are required at port locations above the divertor for complete mapping of all the plasma facing surfaces. The results also show that a rough scan of the entire in-vessel surface can be completed in less than $8 \mathrm{hr}$, if all the probes can be utilized simultaneously.

\section{REMOTE DEPLOYMENT OF THE METROLOGY PROBE}

The metrology probe will be located outside the cryostat where human access is permitted. The height between the vacuum vessel and the cryostat is $8.7 \mathrm{~m}$, at the top port centerline. Thus a very long linear travel $(-20 \mathrm{~m})$, without compromising the accuracy of the measuring technique. The probe is planned to be introduced into the ultra high vacuum vessel using a vacuum break with appropriate shielding. The details of the probe deployment mechanism, assuming that top ports are available for probe deployment, are being designed.

\section{CONCLUSIONS}

A remote metrology/viewing system, based on Coherent FM Laser Radar, is being designed for ITER in-vessel application. Experiments using a prototype system, made by Coleman Research Corporation, show that the technique has the capability to map the in-vessel surfaces to sub-millimeter accuracy from distances of -20 $\mathrm{m}$. The quality of the metrological image obtained by this technique reveal that the system can also be utilized for remote in-vessel viewing of the reactor, without the need for any illuminating source. The modifications required for adopting this system for application in the ITER environment are being studied. A scheme for remote deployment of the metrology probe also needs to be designed.

\section{REFERENCES}

[1] T. Businaro, 18th Symp. on Fusion Technology, Karlsruhe, Germany, August 22-26, 1994

[2] Barry, R. E., et. al., An Analysis of Metrology Techniques Related to ITER Mapping Requirements, ORNL/TM-600, Sept. 1994, Oak Ridge National Laboratory

[3] Kammerman, G. W., Chapter 1, in Vol.6, Active Electrooptical Systems, Clifton S. Fox, Editor, The Infrared and Electrooptical Systems Handbook, ERIM and SPIE Press, Ann Arbor and Bellingham, WA, 1993.

Refer questions to:

R. E. Barry

Oak Ridge National Laboratory

Robotics and Process Systems Division

P.O. Box 2008, MS 6304

Oak Ridge, TN 37831-6304

(615) 574-7027

barryre@oml.gov 
. $=$ 